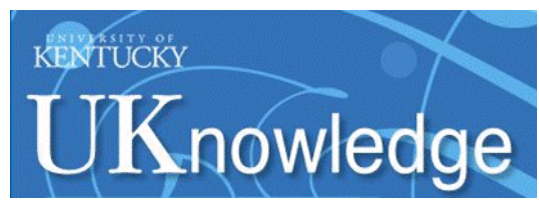

University of Kentucky

UKnowledge

\title{
Gender-Based Harassment in Early Adolescence: Group and Individual Predictors of Perpetration
}

\author{
Michelle Jennine Tam \\ University of Kentucky, michelle.mei.tam@gmail.com \\ Author ORCID Identifier: \\ (iD) https://orcid.org/0000-0002-1884-1014 \\ Digital Object Identifier: https://doi.org/10.13023/etd.2018.421
}

Right click to open a feedback form in a new tab to let us know how this document benefits you.

\section{Recommended Citation}

Tam, Michelle Jennine, "Gender-Based Harassment in Early Adolescence: Group and Individual Predictors of Perpetration" (2018). Theses and Dissertations--Psychology. 150.

https://uknowledge.uky.edu/psychology_etds/150

This Master's Thesis is brought to you for free and open access by the Psychology at UKnowledge. It has been accepted for inclusion in Theses and Dissertations--Psychology by an authorized administrator of UKnowledge. For more information, please contact UKnowledge@lsv.uky.edu. 


\section{STUDENT AGREEMENT:}

I represent that my thesis or dissertation and abstract are my original work. Proper attribution has been given to all outside sources. I understand that I am solely responsible for obtaining any needed copyright permissions. I have obtained needed written permission statement(s) from the owner(s) of each third-party copyrighted matter to be included in my work, allowing electronic distribution (if such use is not permitted by the fair use doctrine) which will be submitted to UKnowledge as Additional File.

I hereby grant to The University of Kentucky and its agents the irrevocable, non-exclusive, and royalty-free license to archive and make accessible my work in whole or in part in all forms of media, now or hereafter known. I agree that the document mentioned above may be made available immediately for worldwide access unless an embargo applies.

I retain all other ownership rights to the copyright of my work. I also retain the right to use in future works (such as articles or books) all or part of my work. I understand that I am free to register the copyright to my work.

\section{REVIEW, APPROVAL AND ACCEPTANCE}

The document mentioned above has been reviewed and accepted by the student's advisor, on behalf of the advisory committee, and by the Director of Graduate Studies (DGS), on behalf of the program; we verify that this is the final, approved version of the student's thesis including all changes required by the advisory committee. The undersigned agree to abide by the statements above.

Michelle Jennine Tam, Student

Dr. Christia Spears Brown, Major Professor

Dr. Mark Fillmore, Director of Graduate Studies 
Gender-Based Harassment in Early Adolescence: Group and Individual Predictors of Perpetration

\section{THESIS}

A thesis submitted in partial fulfillment of the requirements for the degree of Master of Science in the College of Arts and Sciences at the University of Kentucky

By

Michelle Jennine Tam

Lexington, Kentucky

Director: Dr. Christia Spears Brown, Professor of Psychology

Lexington, Kentucky

2018

Copyright ${ }^{\circledR}$ Michelle J. Tam 2018 


\title{
ABSTRACT OF THESIS
}

\section{GENDER-BASED HARASSMENT IN EARLY ADOLESCENCE: GROUP AND INDIVIDUAL PREDICTORS OF PERPETRATION}

\begin{abstract}
The current study examined gender-based harassment in early adolescence and the characteristics of individuals who perpetrate such harassment (specifically, experiences with witnessing gender-based harassment and gender identity). Students in seventh and eighth grade ( $n=483 ; 247$ girls, 236 boys) completed surveys containing measures of gender identity (perceived same and other-gender typicality, felt pressure to conform to gender norms, and gender contentedness), and questions about witnessing and perpetrating teasing, bullying, and rejection because of a peer's gender typicality or atypicality. Results revealed that the more GBH an individual had previously witnessed in their classroom, the more likely they were to report perpetrating GBH themselves. Additionally, boys high in other-gender typicality reported perpetrating more GBH than boys low in other-gender typicality. For girls, same-gender typicality interacted with felt pressure to conform to gender norms to predict GBH perpetration. For girls low in felt pressure, same-gender typicality negatively predicted GBH perpetration. For girls high in felt pressure, same-gender typicality positively predicted GBH perpetration.
\end{abstract}

KEYWORDS: Adolescence, Gender Identity, Gender Typicality, Peers, Teasing 
GENDER-BASED HARASSMENT IN EARLY ADOLESCENCE: GROUP AND INDIVIDUAL PREDICTORS OF PERPETRATION

By

Michelle Jennine Tam
Dr. Christia Spears Brown Director of Thesis

Dr. Mark Fillmore Director of Graduate Studies

$10 / 29 / 18$ 


\section{TABLE OF CONTENTS}

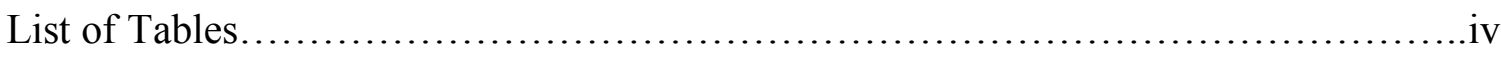

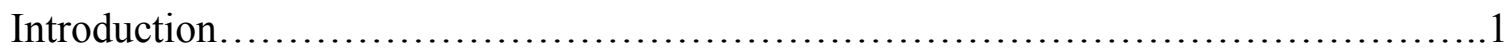

Gender and gender-based harassment............................................

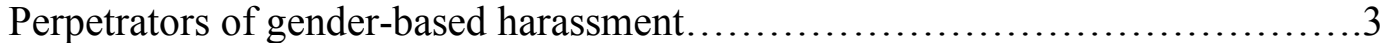

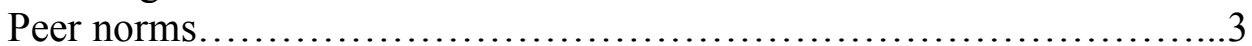

Gender identity......................................................

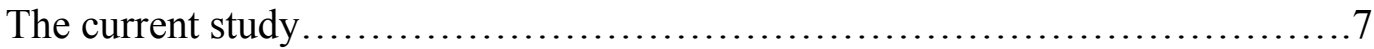

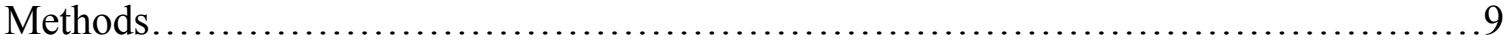

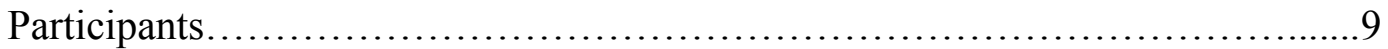

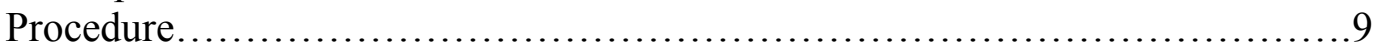

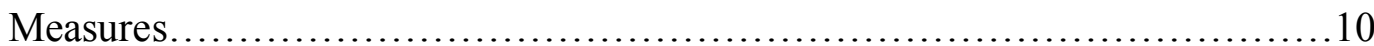

Demographics................................................. 10

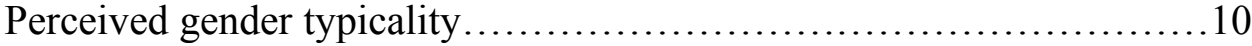

Gender contentment.................................................. 11

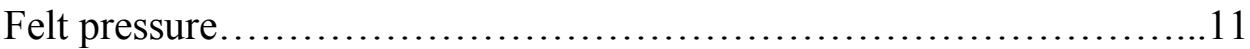

GBH experiences................................................

GBH perpetration...................................................

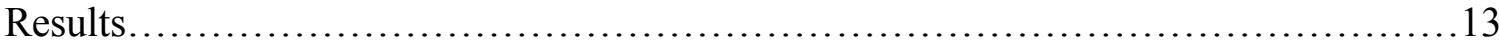

Preliminary analyses and overview...................................... 13

Perpetration of GBH.........................................................

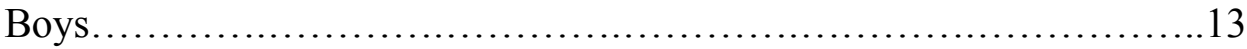

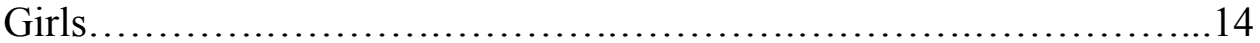

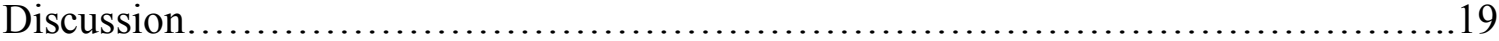

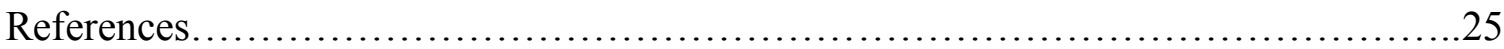

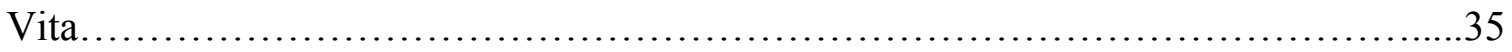




\section{LIST OF TABLES}

Table 1, Means and Standard Deviations for All Variables.............................16

Table 2, Hierarchical Linear Regression Predicting GBH Perpetration for Boys.........17

Table 3, Hierarchical Linear Regression Predicting GBH Perpetration for Girls.........18 
Gender-Based Harassment in Early Adolescence: Group and Individual Predictors of Perpetration

In recent years, highly-publicized reports of teen suicide (Ducharme, 2018) have drawn attention to bullying and harassment targeting youth because of their sexual orientation, gender identity, or gender expression (SOGIE). Adolescents who are considered, in any way, atypical for their gender often face high rates of peer victimization, and as a result, exhibit poorer mental health, physical health, and academic outcomes relative to their more gender-typical peers (Hill \& Kearl, 2011; Jewell \& Brown, 2014; Russell, Kosciw, Horn, \& Saewyc, 2010; Smith \& Juvonen, 2017). Although considerable research has examined the negative effects of harassment on the basis of SOGIE status or gender atypicality, very little research has examined who is perpetrating the harassment. Gaining a better understanding of who is engaging in this gender-based harassment is necessary for effective bullying interventions to be designed

and implemented. Therefore, the current study examined the perpetration of gender-based harassment (GBH; operationally defined here as peer teasing, rejection, and bullying on the basis of gender atypicality) among a sample of early adolescent boys and girls. Specifically, this study focused on whether early adolescent boys and girls are more likely to harass their peers on the basis of gender atypicality when 1) they witness others engaging in similar behaviors, or 2) they themselves feel atypical for their gender and feel pressure to conform to gender norms.

\section{Gender and Gender-Based Harassment}

Every social group has its own specific set of norms, or rules, that differentiate it from other groups (Abrams, Powell, Palmer, \& Van de Vyer, 2017). For children and 
adolescents, gender is a particularly salient social group. From birth, gender is used to sort, label, and organize children (e.g., gender-specific names, colors, toys, and room decorations; see Brown \& Tam, in press, for a review). Developmental intergroup theory argues that this ubiquitous use of gender in a functional way leads children, by early childhood, to focus on gender as a salient group, be highly attentive to gender norms, and develop rigid gender stereotypes regarding the traits, skills, behaviors, and interests appropriate for each gender (Bigler, \& Liben, 2007; Hill \& Flom, 2007; Martin, Wood, \& Little, 1990; Plant, Hyde, Keltner, \& Devine, 2000; Poulin-Dubois, Serbin, Eichstedt, Sen, \& Beissel, 2002). Furthermore, by early adolescence, youth agree on which peers within their classroom are considered gender typical (i.e., they conform to gender stereotypes) and which peers are considered gender atypical (i.e., they do not conform to gender stereotypes; Jewell \& Brown, 2014).

Research has robustly shown that children and adolescents who do not conform to gender norms, or are considered atypical for their gender, are more likely to be verbally teased, rejected or socially excluded, and physically bullied than their more typical peers (D’Augelli, Pilkington, \& Hershberger, 2002; Fagot, 1977; Horn, 2007; Jewell \& Brown, 2014; Kochel, Miller, Updegraff, Ladd, \& Kochenderfer-Ladd, 2012; Toomey, Ryan, Diaz, Card, \& Russell, 2013; Zosuls, Andrews, Martin, England \& Field, 2016). This is consistent with subjective group dynamics theory, which states that deviant group members are often censored or "policed" by their peers in order to encourage conformity (Abrams et al., 2017; Abrams \& Rutland, 2008). Indeed, gender atypicality has been shown to be more important than sexual orientation in predicting peer harassment. Horn (2007) found that high schoolers rated both straight and gay individuals who were seen as 
gender typical as more acceptable than gender atypical individuals (i.e., did not conform to appearance norms), regardless of the individual's sexual orientation.

Research has also clearly and consistently shown that experiencing GBH is associated with negative outcomes for adolescents. For example, relative to their nonvictimized peers, adolescents who experience GBH on the basis of gender atypicality report lower psychological well-being, such as greater depressive symptoms and more anxiety (e.g., Jewell \& Brown, 2014; Mays \& Cochran, 2001; Russell et al., 2010; Smith \& Juvonen, 2017); more negative academic outcomes, such as lower school satisfaction and lower grades (e.g., Hill \& Kearl, 2011; Russell et al., 2010); and more somatic concerns, such as trouble sleeping and loss of appetite (e.g., Espelage, Aragon, Birkett, \& Koenig, 2008; Russell et al., 2010; Smith \& Juvonen, 2017).

\section{Perpetrators of Gender-Based Harassment}

Although considerable research has examined the effects of GBH on the targets of harassment, relatively little research has examined who is actually perpetrating GBH. This represents a fundamental gap in the literature, as understanding the characteristics of individuals who engage in GBH could aid in the development of perpetrator-focused interventions designed to prevent GBH from occurring. Based on similar patterns within the general bullying literature (Barboza et al., 2009; Ojala \& Nesdale, 2004), the current study focused on how perceived peer norms, as well as individual characteristics, are related to early adolescents' GBH perpetration.

Peer norms. Peer norms are extremely influential in adolescence, and adolescents often behave in ways that they perceive to be common or acceptable among their peers (Rimal, 2008). For example, Espelage, Holt, and Henkel (2003) found that the 
level of bullying in an individual's friend group (identified using friendship nominations) predicted their own level of bullying. Additionally, Low, Polanin, and Espelage (2013) found that the average level of aggression within adolescents' friend groups predicted their own aggression over time.

Theoretically, peer norms may be influential for individuals' behavior for several, non-mutually exclusive, reasons. First, individuals may be simply imitating the behaviors of their peers (Bandura, Ross, \& Ross, 1961; Bandura, 1978). Individuals may also be responding to their perceptions of group norms, in that a child or adolescent who witnesses bullying may begin to perceive bullying as acceptable or expected behavior (Salmivalli, 2010). For example, Brown, Clasen, and Eicher (1986) found that adolescents reported more delinquent behavior when they believed that peers expected them to engage in those behaviors. Thus, adolescents who witness bullying may perceive it as the expected social norm, and to conform to that norm, will subsequently bully others.

Previous research on other forms of gender-based harassment has found that friend group norms are predictive of individuals' gendered attitudes and behaviors (Mereish \& Poteat, 2015; Jewell \& Brown, 2013; Jewell, Brown, \& Perry, 2015; Poteat, 2008). For example, using social network analysis, Jewell and colleagues (2015) found that adolescents' perpetration of sexual harassment was homophilous within their friend groups, such that teens reported perpetrating comparable amount of sexual harassment as their friends reported. In addition, perpetration of bullying and harassment targeted towards sexual minorities or perceived sexual minorities within friend groups also predicted youth's own GBH perpetration, controlling for their own individual attitudes 
and behaviors (Poteat 2007; Poteat, 2008; Poteat, Espelage, \& Green, 2007). No previous research has yet examined, however, how group norms surrounding adolescents' GBH perpetration on the basis of gender atypicality, regardless of sexual orientation, is related to their own behaviors.

Additionally, the vast majority of prior research has examined friend groups, rather than general grade-level peer groups. By definition, friends are individuals with reciprocal friendship nominations and mutual liking, while peers are more loosely-linked individuals that spend time together or share activities (e.g., classmates or teammates; Kindermann, 1996; Sage \& KIndermann, 1999; Webb \& Zimmer-Gembeck, 2014). Although many studies do not distinguish between these two types of groups and often use the term "peers" to describe both, the two are not synonymous (Webb \& ZimmerGembeck, 2014). Indeed, friend groups are typically embedded within larger peer groups, and although friends are usually peers, peers are not necessarily friends (Kindermann, 1996; Sage \& Kindermann, 1999; Webb \& Zimmer-Gembeck, 2014). It is important for studies to distinguish between peer and friend groups, as they may have different levels of influence on individuals' behavior (Haselager, Hartup, van Lieshout, \& RiksenWalraven, 1998; Iannotti \& Bush, 1992). To date, most research on GBH perpetration has focused on GBH within the friend group, which is a self-selected, highly similar and influential group of peers (e.g., Birkett \& Espelage, 2015; Poteat, Rivers, \& Vecho, 2015; Poteat \& Spanierman, 2010). The current study, in contrast, focused on whether witnessing GBH within the classroom peer group, which is not self-selected and may be less influential in establishing group norms than friends, was predictive of early adolescents' own GBH perpetration. 
Gender identity. Because targets of GBH are chosen based on how they relate to and fit the normative expectations of their gender group, it is also important to examine how perpetrators feel they relate to and fit in with their gender group. Individuals' adherence to and attitudes about the norms of their gender group are considered part of their gender identity (e.g., Corby, Hodges, \& Perry, 2007; Egan \& Perry, 2001; Martin, Andrews, England, Zosuls, \& Ruble, 2017; Yunger, Carver, \& Perry, 2004). In this context, gender identity (as conceptualized by Egan \& Perry, 2001) refers to the multidimensional construct that includes how typical for their gender individuals perceive themselves to be (i.e., perceived gender typicality), how much pressure they feel to conform to gender norms (i.e., felt pressure), and how content they are with their gender group (i.e., contentedness). Recent research (Martin et al., 2017; Zosuls et al., 2016) has further recognized that feeling typical for one's own gender (i.e., same-gender typicality) is orthogonal from feeling typical for the other gender (i.e., other-gender typicality), and an individual child or adolescent can feel very strongly (or not at all) similar to both girls and boys. It is predicted that each of these components of early adolescents' gender identity will contribute to whether they perpetrate GBH.

Components of gender identity have previously been shown to interact in predicting GBH perpetration (Pauletti, Cooper, \& Perry, 2014). Specifically, preadolescents who were both low in perceived typicality for their own gender group, yet who also felt high pressure to conform to gender norms, increasingly perpetrated more GBH over the course of a year relative to their peers. According to self-discrepancy theory (Higgins, 1987), unpleasant dissonance occurs within individuals when their ought self (who they feel they are expected to be by others) differs from their actual self (who 
they actually are). Consistent with this, Pauletti and colleagues (2014) theorized that youth low in perceived typicality but high in felt pressure to conform may perpetrate GBH because other nonconforming peers "serve as painful mirrors of the children's own inner conflict, and by attacking them, the children can ... repel the threat" (p. 860, 2014).

Research, however, has not fully examined the ways in which youth feel typical or atypical within their gender group. For example, youth who are low in same-gender typicality, but high in other-gender typicality, may feel especially excluded from the group norms. Indeed, children who are low in same-gender and high in other-gender typicality have the lowest self-esteem, are the most asocial, and have the most social anxiety compared to their peers (Martin et al., 2017). According to subject group dynamics theory (Abrams et al., 2017; Abrams \& Rutland, 2008), these youth would be the most deviant group members, and as argued by self-discrepancy theory (Higgins, 1987), may feel the most dissonance between others' expectations of them and their own identity. These youth, when combined with perceiving strong pressure to conform to norms, may be particularly likely to engage in GBH perpetration towards atypical peers. Harassing other atypical peers may help them avoid becoming targets themselves.

\section{The Current Study}

The current study examined the perpetration of gender-based harassment (GBH) among early adolescents (i.e., seventh and eighth graders). This age group was chosen because previous work suggests that the importance of peers may peak at this age. Prior to adolescence, parents are often the largest source of influence in children's lives; this changes during adolescence, when parent influence is often overtaken by peer influence (Greenberg Siegel, \& Leitch, 1983; La Greca \& Lopez, 1998; Rubin, Bukowski, \& 
Parker, 1998). Thus, the impact of peer rejection and harassment may be particularly detrimental at this age. Additionally, adolescence is often called the genderintensification period. When children enter puberty, gender and gender norms increase in both salience and importance (Galambos, Almeia, \& Petersen, 1990; Hill \& Lynch, 1983; Stoddart \& Turiel, 1985). Lastly, prior research has shown that general bullying, as well as biased attitudes towards sexual minorities, may peak at this age (Espelage et al. 2003; Pellegrini, 2002; Poteat, Espelage, \& Koenig, 2009).

Three different types of GBH perpetration were examined among adolescents: verbal teasing, physical bullying, and social rejection. First, it was hypothesized that perceived peer norms would influence adolescents' individual behavior. Specifically, it was predicted that the more GBH an individual had witnessed in their classroom, the more likely they would be to perpetrate GBH themselves. Second, it was hypothesized that individual differences in gender identity would predict adolescents' GBH perpetration. Specifically, it was predicted that individuals who were both low in samegender typicality and high in other-gender typicality would perpetrate more GBH than individuals high in same-gender typicality or low in other-gender typicality. It was further predicted that the relationship between same and other-gender typicality and GBH perpetration would be moderated by felt pressure to conform. Specifically, it was predicted that, among individuals who were low in same-gender typicality and high in other-gender typicality, they would be most likely to perpetrate GBH when they felt high pressure to conform to gender norms. These models controlled for overall levels of gender contentedness to tease apart felt group norm pressures from overall happiness with one's gender category. 


\section{Methods}

\section{Participants}

The participants of this study were a part of a larger study conducted at a public middle school. There were 483 seventh and eighth grade students, ages 11-15 $(M=12.74$ years, $S D=.68$ years). There were 247 girls and 236 boys. Participants were recruited for this study using passive consent. Consent forms were sent home with all seventh and eighth grade students two weeks prior to data collection. An e-mail was also sent to parents instructing them to fill out and return the attached form if they did not want their child to participate in the study. At the time of the study, there were 706 seventh and eighth grade students enrolled at the school. Twelve parents returned forms indicating that they did not want their child to participate, and 15 students chose not to participate. Seventy other students were excluded from data collection due to abbreviated schedules (i.e., alternative classes) that made it impossible to complete surveys during class time. Thirteen students were removed from data collection due to being enrolled in special education classes and thus experiencing higher rates of harassment than their peers for reasons unrelated to the study. Of the 596 students who complete the survey, 113 were removed due to missing data, resulting in the final sample of 483 students. The sample was primarily European American, with $61.4 \%$ self-reporting as White, $16.8 \%$ as African American, 5.2\% as Hispanic/Latino, 4.6\% as Asian American, and 12\% as other or

biracial. This ethnic distribution was representative of the school as a whole, as well as of the city in which the school was located.

\section{Procedure}


Students whose parents gave passive consent and who had themselves given assent completed several gender-specific survey packets under the supervision of research assistants. Data collection took place within the classroom during a normal school day. Trained research assistants read the instructions to each classroom, after which students were allowed to complete the survey packets on their own. Packets included demographic information, measures of gender identity, and questions about perpetrating and witnessing GBH. Students who completed their surveys were given a university folder and were entered into a drawing for one of four \$50 Amazon gift cards.

\section{Measures}

Demographics. Students reported their ethnicity, age, self-identified gender, family composition (e.g., one vs. two-parent household), and family socioeconomic status (i.e., parental education, occupation, and income).

Perceived gender typicality. Perceived gender typicality was assessed using the same-gender (5 items) and other-gender (5 items) similarity scale (Martin et al., 2017). Students were asked to rate how similar they feel to both boys and girls in general and across several domains (e.g., "How much do you like to do the same things as other boys/girls?" or "How much do you look like other boys/girls?"), on a scale of 1 (not at all) to 4 (a lot). Internal consistency for same-gender typicality was good $(\alpha=.82)$, but only acceptable for other-gender typicality $(\alpha=.71)$. The question, "How much do you like to spend time with other boys/girls?" was the only question that did not directly address gender similarity (i.e., one could be dissimilar to other-gender peers but still like to spend time with them); deleting this item from the scale improved the internal consistency $(\alpha=.76)$. For consistency across scales, the same question was also dropped 
from same-gender typicality $(\alpha=.82)$. Means of the remaining 4 items were calculated for each scale, with higher scores indicating more similarity to either same or other gender.

Gender contentment. Children's contentedness with their gender was assessed using the gender contentment subscale (6 items) of the gender identity scale (adapted by Carver, Yunger, \& Perry, 2003, from Egan \& Perry, 2001). Students were asked to rate how happy they were to be their gender (e.g., "I feel cheated that there are some things I'm not supposed to do just because I'm a girl.”) on a 1 (not at all) to 4 (a lot) scale. Internal consistency was acceptable $(\alpha=.71)$. The item "I think it's fair that some things are only for boys" was reverse coded, which can often lead to misresponse and diminished scale reliability (Swain, Weathers, and Niedrich, 2008; Weijters, Baumgartner, \& Schillewaet, 2013). Thus, this item was dropped, resulting in improved internal consistency $(\alpha=.79)$. Means of the remaining 5 items were calculated, with higher scores indicating greater gender contentment.

Felt pressure. The pressure children feel to conform to traditional gender roles was assessed using the felt pressure to conform subscale ( 8 items) of the gender identity scale (adapted by Carver et al., 2003, from Egan \& Perry, 2001). Students were asked to rate how much they feel that parents and peers expect them to conform to gender norms (e.g., "I think my parents would be upset if I wanted to learn an activity that only boys usually do.”) on a 1 (not at all) to 4 (a lot) scale. Means were calculated, with higher scores indicating greater felt pressure to conform. Internal consistency was excellent ( $\alpha$ $=.91)$. 
GBH experiences. To assess students' experiences with witnessing gender-based harassment, they were read a short paragraph and asked about their experiences with witnessing verbal teasing, physical bullying, and social rejection. Specifically, students were told "Some people treat their classmates differently just because they do not act like a typical boy or girl. This includes teasing a girl for wearing boys' clothes, calling a boy a bad name for being too girly, teasing a boy because he does ballet, and similar behaviors. Some people think these things happen in their classrooms. Other people don't think these things happen in their classroom. We want to know about your own experiences within this classroom only." Students' classrooms were used as a proxy for their peer group. Students were then asked whether or not they had ever seen someone experience verbal, physical, or exclusionary GBH. Students were asked "In the past month, have you seen a boy (girl) get 1) verbally teased or made fun of, 2) physically bullied, or 3) rejected or left out, for not being boyish (girlish) enough?” Answers were scored 1 (no), 2 (yes, once or twice), 3 (yes, a few times), and 4 (yes, many times). Means for witnessing the three types of GBH were calculated, with higher scores indicating more instances of witnessing GBH.

GBH perpetration. To assess students' perpetration of GBH, they were asked to think about how many times in the last month they have verbally teased, physically bullied, and rejected someone at school. They were asked, "In the past month, have you 1) verbally teased or made fun of, 2) physically bullied, or 3) rejected or left out someone for not being a typical boy (girl)?” Answers were scored 1 (no), 2 (yes, once or twice), 3 (yes, a few times), and 4 (yes, many times). Means for perpetrating the three types of GBH were calculated, with higher scores indicating more instances of perpetrating GBH. 


\section{Results}

\section{Preliminary Analyses and Overview}

Table 1 shows the mean and standard deviations for all variables by gender. As indicated by t-tests, there were significant gender differences for same and other-gender typicality, felt pressure, and gender contentment. Girls scored higher on other-gender typicality. Boys scored higher on same-gender typicality, felt pressure, and gender contentment than girls. There were no gender differences in experiencing or perpetrating GBH. Because of these gender differences in gender identity, boys' and girls' selfreported perpetration of GBH were analyzed separately using hierarchical linear multiple regression (see Table 2 and Table 3, respectively).

For all analyses, age and gender contentedness were entered in the first step as controls. To test the key hypotheses, the mean of witnessing GBH was entered in the second step (the more distal factor was entered into the model before the individual factors). The mean same-gender (SG), other-gender (OG) typicality, and felt pressure were entered in the third step (all mean-centered), and critically, the interaction between SG and OG typicality was entered in the fourth step. To test the hypothesis about moderation, the fifth and sixth steps included the two-way interactions (SG typicality X felt pressure, OG typicality X felt pressure) and three way interaction (SG typicality X OG typicality X felt pressure) respectively. All interactions were calculated with meancentered variables.

\section{Perpetration of GBH}

Boys. As can be seen in Table 2, having previously witnessed GBH was a significant predictor of boys' perpetration of $\operatorname{GBH}(\beta=.44, t(232)=7.17, p<.001)$, 
explaining $18 \%$ of the variance. As expected, boys who reported witnessing more GBH reported perpetrating more GBH as well. Other-gender typicality was also a significant predictor of GBH perpetration $(\beta=.14, t(229)=2.15, p=.03)$, explaining an additional, and significant, $3 \%$ of the variance. Boys higher in other-gender typicality reported perpetrating more GBH. Other-gender typicality was not further moderated by samegender typicality or felt pressure to conform.

Girls. As can be seen in Table 3, for girls, having previously witnessed GBH was also a significant predictor of perpetrating GBH $(\beta=.34, t(243)=5.54, p<.001)$, explaining $10 \%$ of the variance. As expected, girls who had witnessed more GBH reported perpetrating more GBH. In the fifth step, the interaction between same-gender typicality and felt pressure to conform to gender norms was also significant $(\beta=.31$, $t(237)=3.06, p=.002)$ and explained a significant amount of unique variance. To examine the significant interaction, we compared the simple slopes of same-gender typicality among girls who had been recoded into two groups: high felt pressure to conform ( $>1$ SD above the mean) and low felt pressure to conform $(<1 \mathrm{SD}$ below the mean). Analyses indicated that, among girls who felt low pressure to conform to gender norms, increased same-gender typicality predicted lower GBH perpetration $(B=-.23)$. However, among girls who felt high pressure to conform, increased same-gender typicality predicted higher GBH perpetration $(B=.26)$. The interaction between othergender typicality and felt pressure to conform to gender norms was also significant ( $\beta$ $=.19, t(237)=2.03, p=.04)$. To examine this interaction, as before, we compared the simple slopes of other-gender typicality for girls who felt high pressure to conform and low pressure to conform. Analyses indicated that, among girls who felt low pressure to 
conform to gender norms, increased other-gender typicality predicted lower GBH perpetration $(B=-.04)$. However, among girls who felt high pressure to conform, increased other-gender typicality predicted higher GBH perpetration $(B=.04)$. 
Table 1. Means and Standard Deviations for All Variables

\begin{tabular}{lllll}
\hline Variable & Combined & Boys & Girls & T-test \\
\hline Same-gender typicality & $3.31(.66)$ & $3.49(.57)$ & $3.13(.70)$ & $6.26, p<.001$ \\
Other-gender typicality & $1.54(.58)$ & $1.27(.40)$ & $1.80(.60)$ & $-11.39, p<.001$ \\
Felt pressure & $2.11(.90)$ & $2.58(.91)$ & $1.66(.60)$ & $13.09, p<.001$ \\
Gender contentment & $3.21(.68)$ & $3.59(.45)$ & $2.85(.66)$ & $14.39, p<.001$ \\
GBH (Witness) & $1.37(.50)$ & $1.35(.51)$ & $1.39(.50)$ & $-.76, p=.45$ \\
GBH (Perpetrator) & $1.09(.25)$ & $1.11(.29)$ & $1.08(.20)$ & $1.22, p=.22$ \\
\hline Means are listed first, with standard deviations in parentheses. All variables used a 1-4 \\
\multicolumn{5}{l}{ scale. Significant t-tests indicate significant gender differences. }
\end{tabular}


Table 2. Hierarchical Linear Regression Predicting GBH Perpetration for Boys

\begin{tabular}{|c|c|c|c|c|c|c|}
\hline Variable & Model 1 & Model 2 & Model 3 & Model 4 & Model 5 & Model 6 \\
\hline Age & .09 & .05 & .05 & .05 & .04 & .04 \\
\hline Gender contentment & -.05 & .06 & .11 & .11 & .12 & .11 \\
\hline GBH (Witness) & - & $.44 * *$ & $.41^{* *}$ & $.41 * *$ & $.41 * *$ & $.41^{* *}$ \\
\hline SG & - & - & -.05 & -.10 & -.08 & -.12 \\
\hline OG & - & - & $.14 *$ & $.13^{*}$ & .11 & .11 \\
\hline Felt pressure & - & - & .11 & .10 & .15 & $.17^{*}$ \\
\hline SG x OG & - & - & - & -.11 & -.11 & $-.18^{*}$ \\
\hline SG $\times$ Felt pressure & - & - & - & - & -.05 & .01 \\
\hline OG $x$ Felt pressure & - & - & - & - & .05 & .06 \\
\hline $\begin{array}{l}\text { SG X OG x Felt } \\
\text { pressure }\end{array}$ & - & - & - & - & - & .13 \\
\hline $\mathrm{R}^{2}\left(\right.$ Sig. $\left.\Delta \mathrm{R}^{2}\right)$ & .001 & $.18^{* *}$ & $.20^{*}$ & .21 & .20 & .21 \\
\hline$F_{\text {model }}$ & 1.12 & $18.02^{* *}$ & $10.69^{* *}$ & $9.70^{* *}$ & $7.63 * *$ & $7.07 * *$ \\
\hline
\end{tabular}


Table 3. Hierarchical Linear Regression Predicting GBH Perpetration for Girls

\begin{tabular}{|c|c|c|c|c|c|c|}
\hline Variable & Model 1 & Model 2 & Model 3 & Model 4 & Model 5 & Model 6 \\
\hline Age & .04 & .05 & .05 & .05 & .08 & .08 \\
\hline Gender contentment & .02 & .04 & .01 & .01 & .06 & .06 \\
\hline GBH (Witness) & - & $.34 * *$ & $.34 * *$ & $.34 * *$ & $.34 * *$ & $.35^{* *}$ \\
\hline SG & - & - & .06 & .03 & $.20 *$ & .20 \\
\hline OG & - & - & -.04 & -.01 & .10 & .11 \\
\hline Felt pressure & - & - & .04 & .03 & .09 & .09 \\
\hline $\mathrm{SG} \times \mathrm{OG}$ & - & - & - & .08 & .09 & .10 \\
\hline SG x Felt pressure & - & - & - & - & $.31 * *$ & $.30^{*}$ \\
\hline OG $x$ Felt pressure & - & - & - & - & $.19^{*}$ & .20 \\
\hline $\begin{array}{l}\text { SG X OG x Felt } \\
\text { pressure }\end{array}$ & - & - & - & - & - & .02 \\
\hline $\mathrm{R}^{2}\left(\right.$ Sig. $\left.\Delta \mathrm{R}^{2}\right)$ & -.007 & $.10^{* *}$ & .10 & .10 & $.13^{* *}$ & .12 \\
\hline$F_{\text {model }}$ & .20 & $10.40^{* *}$ & $5.49^{* *}$ & $4.84 * *$ & $4.96^{* *}$ & $4.45^{* *}$ \\
\hline
\end{tabular}




\section{Discussion}

The relationship between gender atypicality (i.e., not conforming to gender group norms) and experiencing gender-based harassment has been well-documented, and individuals who are atypical for their own gender or more typical of the other gender often face high rates of harassment from their peers (D'Augelli et al., 2002; Horn, 2007; Jewell \& Brown, 2014; Kochel et al., 2012; Toomey et al., 2013). However, less research has examined how gender typicality is related to the perpetration of gender-based harassment. Additionally, while previous work (e.g., Birkett \& Espelage, 2015; Poteat et al., 2015; Poteat \& Spanierman, 2010) has largely examined how adolescents' genderbased harassment behaviors are connected to their friend groups, less research has examined how the perpetration of gender-based harassment is related to the classroomlevel peer group. These were the goals of the current study

First, as hypothesized, results indicated that boys and girls who had previously witnessed their peers engage in gender-based harassment reported perpetrating more gender-based harassment themselves. This is consistent with previous research that has shown that adolescents often engage in behaviors they believe to be common among peers (AAUW, 2001; Jewell et al., 2015; Rimal, 2008) and that the average levels of bullying and aggression in an individual's friend group are associated with their own bullying and aggression (Espelage et al., 2003; Low et al., 2013; Poteat, 2007; Poteat, 2008; Poteat et al., 2015). This research extends previous research by indicating that individuals' GBH perpetration is also related to their perceptions of their broader peer groups' GBH perpetration. This suggests that a close, affective tie (e.g., friendship) is not necessary to establish influential group norms for behaviors. It is important to recognize, 
however, that individuals who perpetrate more GBH are also likely noticing more GBH perpetrated by their peers. Thus, it is not suggested that the direction of effects is unidirectional. Rather, it is probable that the more adolescents notice others perpetrating $\mathrm{GBH}$, the more they perpetrate it themselves; and the more they perpetrate it themselves, the more salient it becomes, making them more likely to notice others' future perpetration of GBH. Future longitudinal research, utilizing multiple time points across early adolescence, should be conducted to explore the directionality of this relationship.

Second, as hypothesized, results from the current study indicated that gender typicality also predicted the perpetration of gender-based harassment, although this differed for boys and girls. Specifically, after controlling for contentedness with gender and experiences witnessing GBH, boys who were high in other-gender typicality were more likely to perpetrate GBH than boys who were low in other-gender typicality. Interestingly, being low in same-gender typicality did not predict perpetrating GBH. In other words, boys who felt highly similar to girls, regardless to how happy they were with their gender or how similar they felt to boys, perpetrated more gender-based harassment than boys who did not feel similar to girls. Critically, this finding supports the dual identity model proposed by Martin and colleagues (2017), in that perceived typicality to the same gender and typicality to the other gender were differentially related to outcomes. In the current context, it may be that boys who were high in other-gender typicality were considered the most deviant (Abrams \& Rutland, 2008), and thus experienced the largest discrepancy between the ought self (who one is expected to be by others) and actual self (who one actually is; Higgins, 1987). Conforming to the ought-self may be a way to escape disapproval or censorship from others, and these individuals may 
attempt to conform by engaging in what they believe to be common group behaviors (e.g., harassing gender-atypical peers; Carver \& Scheier, 1998; Ryan, Rigby, \& King, 1993). By engaging in these "group" behaviors, other-gender typical boys may avoid censorship (e.g., being harassed themselves).

For girls, the degree to which they felt pressure to conform to gender norms determined the relationship between their gender typicality and GBH perpetration. Specifically, among girls who felt low pressure to conform, same-gender typicality negatively predicted GBH perpetration. In other words, girls who felt highly similar to other girls, but who perceived little external pressure to conform (i.e., girls who are unlikely to be the target of GBH themselves), seemed to refrain from engaging in the gender-based harassment of others. It is likely that these girls, who are gender typical without feeling conformity pressures, experience little discrepancy between the ought self and the actual self (Higgins, 1987), and thus are less motivated to harass gender-atypical others.

In contrast, among girls who felt strong pressure to conform, those who were high in same-gender typicality perpetrated more GBH than less typical girls. In other words, girls who felt highly similar to other girls, but did so while feeling external pressures to conform to those gender norms, reported perpetrating more GBH than less typical girls. It may be that when girls felt high pressure to conform, giving in to that pressure and conforming to the norms prompted them to then harass others into conforming as well. Although other-gender typicality also interacted with felt pressure to predict GBH perpetration, the size of the simple slopes $(B=-.04$ and .04$)$ were so small that the interactions were not interpreted. 
It is unclear why other-gender typicality was a significant predictor of boys' GBH perpetration and same-gender typicality was a significant predictor for girls. There were overall gender differences in perceived gender typicality. Although both boys and girls tended to report high levels of same-gender typicality ( $M>3$ on a scale of 1 to 4$)$ and low levels of other-gender typicality ( $M<2$ on a scale of 1 to 4 ), girls were significantly higher in other-gender typicality than boys and boys were higher in same-gender typicality than girls. Taken together, this finding indicates that both boys and girls felt asymmetrical similarity to boys. Boys also reported higher felt pressure and gender contentment than girls. These gender differences are consistent with previous research. Prior work has shown that girls often experience laxer gender norms and report lower felt pressure to conform than boys (Corby et al., 2007; Egan \& Perry, 2001; Lee \& TroopGordon, 2011; Zosuls et al., 2016). Girls face less drastic consequences for embodying cross-gender norms than boys and often exhibit higher other-gender typicality than boys, while boys exhibit higher same-gender typicality than girls (Andrews, Martin, \& Gallagher, 2016; Carter \& McCloskey, 1983; Fagot, 1977; Zosuls et al., 2016). Yet, in the current study, it was both boys' and girls' similarity to girls that predicted their GBH perpetration; namely, boys who felt similar to girls and girls who felt similar to girls while also feeling pressure to conform to norms perpetrated the most GBH of the sample. Despite these differences, there were no overall gender differences in the reported perpetration of GBH (although this is inconsistent with previous research that indicates that boys perpetrate more GBH than girls; Poteat et al., 2009; Rinehart \& Espelage, 2016). Future research should explore why perceived similarity to girls seems to predict GBH perpetration for both boys and girls. 
As with all research, there are limitations to the current study. First, this study used self-report measures of gender typicality. Although previous work has shown that self- and peer-report measures of gender typicality are highly related (Jewell \& Brown, 2014), future research should examine gender typicality from multiple sources.

Additionally, the study used self-report measures of experiences with witnessing and perpetrating $\mathrm{GBH}$. The reported rates of witnessing and perpetrating $\mathrm{GBH}$ were relatively low, and it could be that GBH was simply less salient to some individuals than to others. For example, Wessler and De Andrade (2006) found that students often perceive biased language to have alternative meanings (e.g., using "gay" to mean "stupid"); thus, it is possible that students witnessed higher rates of GBH than reported here, but did not interpret it as gendered teasing, bullying, or rejection. Future work should examine the meaning that adolescents attach to biased language and behavior and the contexts in which they perceive it to be harmful. Finally, this study was conducted at only one time point. Previous research suggests that the importance of group norms may lessen across adolescence (Brown et al., 1986), and future research should follow adolescents longitudinally to determine the influence of peer norms and gender typicality on GBH over time.

Despite these limitations, however, the current study represents an important step towards understanding the characteristics of individuals who perpetrate gender-based harassment. Early adolescents who witness peers perpetrating GBH are more likely to do so themselves. Early adolescent boys who are high in other-gender similarity (i.e., who do not conform to group norms) are not just more likely to be harassed (Horn, 2007; Jewell \& Brown, 2014; Toomey et al, 2013), but are also more likely to be harassers 
themselves. For girls, predicting GBH perpetration is a function of both same-gender typicality and felt pressure to conform. This has implications for GBH interventions, as they must 1) target peer groups, not just individual perpetrators and their friends, 2) consider individuals simultaneously as both targets and perpetrators, and 3) account for the differential socialization and normative conformity pressures for both boys and girls. 


\section{References}

AAUW. (2001). Hostile hallways: Bullying, teasing and sexual harassment in school. Washington, DC: American Association of University Women Educational Foundation.

Abrams, D., Powell, C., Palmer, S.B., \& Van de Vyer, J. (2017). Toward a contextualized social developmental account of children's group-based inclusion and exclusion: The developmental model of subjective group dynamics. In A. Rutland, D. Nesdale, \& C.S. Brown (Eds.), The Wiley handbook of group processes in children and adolescents (pp. 124-143). West Sussex, UK: Wiley-Blackwell.

Abrams, D., \& Rutland, A. (2008). The development of subjective group dynamics. In S.R. Levy \& M. Killen (Eds.), Intergroup attitudes and relations in childhood through adulthood (pp. 47-65). New York, NY: Oxford University Press.

Andrews, N. C. Z., Martin, C. L., \& Gallagher, A. M. (2016). On the association between self-reported own- and other-gender similarity and the use of physical and relational aggression in sixth grade children. Archives of Sexual Behavior, 45(7), 1817-1826. doi: 10.1007/s10508-015-0685-Z

Bandura, A. (1978). Social learning theory of aggression. Journal Of Communication, 28(3), 12-29. doi:10.1111/j.1460-2466.1978.tb01621.x

Bandura, A., Ross, D., \& Ross, S. A. (1961). Transmission of aggression through imitation of aggressive models. The Journal Of Abnormal And Social Psychology, 63(3), 575-582. doi:10.1037/h0045925

Barboza, G. E., Schiamberg, L. B., Oehmke, J., Korzeniewski, S. J., Post, L. A., \& Heraux, C. G. (2009). Individual characteristics and the multiple contexts of 
adolescent bullying: An ecological perspective. Journal Of Youth And Adolescence, 38(1), 101-121. doi:10.1007/s10964-008-9271-1

Bigler, R. S., \& Liben, L. S. (2007). Developmental intergroup theory: Explaining and reducing children's social stereotyping and prejudice. Current Directions In Psychological Science, 16(3), 162-166. doi:10.1111/j.1467-8721.2007.00496.x

Birkett, M., \& Espelage, D. L. (2015). Homophobic name-calling, peer-groups, and masculinity: The socialization of homophobic behavior in adolescents. Social Development, 24(1), 184-205. doi:10.1111/sode.12085

Brown, B. B., Clasen, D. R., \& Eicher, S. A. (1986). Perceptions of peer pressure, peer conformity dispositions, and self-reported behavior among adolescents. Developmental Psychology, 22(4), 521-530. doi:10.1037/00121649.22.4.521

Brown, C.S., \& Tam, M.J. (in press). Parenting girls and boys. In M.H. Bornstein (Ed.), Handbook of parenting (3rd ed.). New York, NY: Routledge.

Carter, D. B., \& McCloskey, L. A. (1983). Peers and the maintenance of sex-typed behavior: The development of children's conceptions of cross-gender behavior in their peers. Social Cognition, 2(4), 294-314. doi:10.1521/soco.1984.2.4.294

Carver, C. S., \& Scheier, M. F. (1998). On the self-regulation of behavior. New York, NY, US: Cambridge University Press. doi:10.1017/CBO9781139174794

Carver, P. R., Yunger, J. L., \& Perry, D. G. (2003). Gender identity and adjustment in middle childhood. Sex Roles, 49(3-4), 95-109. doi:10.1023/A:1024423012063

Corby, B. C., Hodges, E. E., \& Perry, D. G. (2007). Gender identity and adjustment in black, Hispanic, and white preadolescents. Developmental Psychology, 43(1), 
261-266. doi:10.1037/0012-1649.43.1.261

D'Augelli, A. R., Pilkington, N. W., \& Hershberger, S. L. (2002). Incidence and mental health impact of sexual orientation victimization of lesbian, gay, and bisexual youths in high school. School Psychology Quarterly, 17(2), 148-167. doi:10.1521/scpq.17.2.148.20854

Ducharme, J. (2018, August 28). A 9-Year-old Colorado boy's death by suicide highlights the challenges facing LGBTQ kids. Time. Retrieved from http://time.com/5380203/lgbtq-youth-suicide/

Egan, S. K., \& Perry, D. G. (2001). Gender identity: A multidimensional analysis with implications for psychosocial adjustment. Developmental Psychology, 37(4), 451463. doi:10.1037/0012-1649.37.4.451

Espelage, D. L., Aragon, S. R., Birkett, M., \& Koenig, B. W. (2008). Homophobic teasing, psychological outcomes, and sexual orientation among high school students: What influence do parents and schools have?. School Psychology Review, 37(2), 202-216.

Espelage, D. L., Holt, M. K., \& Henkel, R. R. (2003). Examination of peer-group contextual effects on aggression during early adolescence. Child Development, 74(1), 205-220. doi:10.1111/1467-8624.00531

Fagot, B. I. (1977). Consequences of moderate cross-gender behavior in preschool children. Child Development, 48(3), 902-907. doi:10.2307/1128339

Galambos, N. L., Almeida, D. M., \& Petersen, A. C. (1990). Masculinity, femininity, and sex role attitudes in early adolescence: Exploring gender intensification. Child Development, 61(6), 1905-1914. doi:10.2307/1130846 
Greenberg, M. T., Siegel, J. M., \& Leitch, C. J. (1983). The nature and importance of attachment relationships to parents and peers during adolescence. Journal Of Youth And Adolescence, 12(5), 373-386. doi:10.1007/BF02088721

Haselager, G. T., Hartup, W. W., van Lieshout, C. M., \& Riksen-Walraven, J. A. (1998). Similarities between friends and nonfriends in middle childhood. Child Development, 69(4), 1198-1208. doi:10.2307/1132369

Higgins, E. T. (1987). Self-discrepancy: A theory relating self and affect. Psychological Review, 94(3), 319-340. doi:10.1037/0033-295X.94.3.319

Hill, S. E., \& Flom, R. (2007). 18- and 24-month-olds' discrimination of genderconsistent and inconsistent activities. Infant Behavior \& Development, 30(1), 168173. doi:10.1016/j.infbeh.2006.08.003

Hill, C., \& Kearl, H. (2011). Crossing the line: Sexual harassment at school (No. 978-18799-2241-9). Washington, DC: American Association of University Women.

Horn, S. S. (2007). Adolescents' acceptance of same-sex peers based on sexual orientation and gender expression. Journal Of Youth And Adolescence, 36(3), 363-371. doi:10.1007/s10964-006-9111-0

Iannotti, R. J., \& Bush, P. J. (1992). Perceived vs. actual friends' use of alcohol, cigarettes, marijuana, and cocaine: Which has the most influence?. Journal Of Youth And Adolescence, 21(3), 375-389. doi:10.1007/BF01537024

Jewell, J. A., \& Brown, C. S. (2013). Sexting, catcalls, and butt slaps: How gender stereotypes and perceived group norms predict sexualized behavior. Sex Roles: $A$ Journal of Research, 69(11-12), 594-604. doi:10.1007/s11199-013-0320-1

Jewell, J. A., \& Brown, C. S. (2014). Relations among gender typicality, peer relations, 
and mental health during early adolescence. Social Development, 23(1), 137-156. doi:10.1111/sode. 12042

Jewell, J., Brown, C. S., \& Perry, B. (2015). All my friends are doing it: Potentially offensive sexual behavior perpetration within adolescent social networks. Journal Of Research On Adolescence, 25(3), 592-604. doi:10.1111/jora.12150

Kinderman, T. A. (1996). Strategies for the study of individual development within naturally-existing peer groups. Social Development, 5(2), 158-173. doi:10.1111/j.1467-9507.1996.tb00078.x

Kochel, K. P., Miller, C. F., Updegraff, K. A., Ladd, G. W., \& Kochenderfer-Ladd, B. (2012). Associations between fifth graders' gender atypical problem behavior and peer relationships: A short-term longitudinal study. Journal Of Youth And Adolescence, 41(8), 1022-1034. doi:10.1007/s10964-011-9733-8

La Greca, A. M., \& Lopez, N. (1998). Social anxiety among adolescents: Linkages with peer relations and friendships. Journal Of Abnormal Child Psychology, 26(2), 8394. doi:10.1023/A:1022684520514

Lee, E. E., \& Troop-Gordon, W. (2011). Peer processes and gender role development: Changes in gender atypicality related to negative peer treatment and children's friendships. Sex Roles, 64(1-2), 90-102. doi:10.1007/s11199-010-9883-2

Low, S., Polanin, J. R., \& Espelage, D. L. (2013). The role of social networks in physical and relational aggression among young adolescents. Journal Of Youth And Adolescence, 42(7), 1078-1089. doi:10.1007/s10964-013-9933-5

Martin, C. L., Andrews, N. Z., England, D. E., Zosuls, K., \& Ruble, D. N. (2017). A dual identity approach for conceptualizing and measuring children's gender identity. 
Child Development, 88(1), 167-182. doi:10.1111/cdev.12568

Martin, C. L., Wood, C. H., \& Little, J. K. (1990). The development of gender stereotype components. Child Development, 61(6), 1891-1904. doi:10.2307/1130845

Mays, V. M., \& Cochran, S. D. (2001). Mental health correlates of perceived discrimination among lesbian, gay, and bisexual adults in the United States. American Journal Of Public Health, 91(11), 1869-1876. doi:10.2105/AJPH.91.11.1869

Mereish, E., \& Poteat, V. P. (2015). Effects of heterosexuals' direct and extended friendships with sexual minorities on their attitudes and behaviors: Intergroup anxiety and attitude strength as mediators and moderators. Journal Of Applied Social Psychology, 45(3), 147-157. doi:10.1111/jasp.12284

Ojala, K., \& Nesdale, D. (2004). Bullying and social identity: The effects of group norms and distinctiveness threat on attitudes towards bullying. British Journal Of Developmental Psychology, 22(1), 19-35. doi:10.1348/026151004772901096

Pauletti, R. E., Cooper, P. J., \& Perry, D. G. (2014). Influences of gender identity on children's maltreatment of gender-nonconforming peers: A person $\times$ target analysis of aggression. Journal Of Personality And Social Psychology, 106(5), 843-866. doi:10.1037/a0036037

Pellegrini, A. D. (2002). Bullying, victimization, and sexual harassment during the transition to middle school. Educational Psychologist, 37(3), 151-163. doi:10.1207/S15326985EP3703_2

Plant, E. A., Hyde, J. S., Keltner, D., \& Devine, P. G. (2000). The gender stereotyping of emotions. Psychology Of Women Quarterly, 24(1), 81-92. doi:10.1111/j.1471- 
6402.2000.tb01024.x

Poulin-Dubois, D., Serbin, L. A., Eichstedt, J. A., Sen, M. G., \& Beissel, C. F. (2002). Men don't put on make-up: Toddlers' knowledge of the gender stereotyping of household activities. Social Development, 11(2), 166-181. doi:10.1111/14679507.00193

Poteat, V. P. (2007). Peer group socialization of homophobic attitudes and behavior during adolescence. Child Development, 78(6), 1830-1842. doi:10.1111/j.14678624.2007.01101.x

Poteat, V. P. (2008). Contextual and moderating effects of the peer group climate on use of homophobic epithets. School Psychology Review, 37(2), 188-201.

Poteat, V. P., Espelage, D. L., \& Green, H. J. (2007). The socialization of dominance: Peer group contextual effects on homophobic and dominance attitudes. Journal Of Personality And Social Psychology, 92(6), 1040-1050. doi:10.1037/00223514.92.6.1040

Poteat, V. P., Espelage, D. L., \& Koenig, B. W. (2009). Willingness to remain friends and attend school with lesbian and gay peers: Relational expressions of prejudice among heterosexual youth. Journal of Youth and Adolescence, 38(7), 952-962. doi:10.1007/s10964-009-9416-X

Poteat, V. P., Rivers, I., \& Vecho, O. (2015). The role of peers in predicting students' homophobic behavior: Effects of peer aggression, prejudice, and sexual orientation identity importance. School Psychology Review, 44(4), 391-406. doi.org/10.17105/spr-15-0037.1

Poteat, V. P., \& Spanierman, L. B. (2010). Do the ideological beliefs of peers predict the 
prejudiced attitudes of other individuals in the group?. Group Processes \& Intergroup Relations, 13(4), 495-514. doi:10.1177/1368430209357436

Rimal, R. (2008). Modeling the relationship between descriptive norms and behaviors: A test and extension of the theory of normative social behavior (TNSB). Health Communication, 23, 103-116. doi:10. 1080/10410230801967791.

Rinehart, S. J., \& Espelage, D. L. (2016). A multilevel analysis of school climate, homophobic name-calling, and sexual harassment victimization/perpetration among middle school youth. Psychology of Violence, 6(2), 213-222. doi:10.1037/a0039095

Rubin, K. H., Bukowski, W., \& Parker, J. G. (1998). Peer interactions, relationships, and groups. In N. Eisenberg, N. Eisenberg (Eds.), Handbook of child psychology: Social, emotional, and personality development (pp. 619-700). Hoboken, NJ, US: John Wiley \& Sons Inc.

Russell, S. T., Kosciw, J., Horn, S., \& Saewyc, E. (2010). Safe schools policy for LGBTQ students. SRCD Social Policy Report, 24(4), 1-17.

Ryan, R. M., Rigby, S., \& King, K. (1993). Two types of religious internalization and their relations to religious orientations and mental health. Journal of Personality and Social Psychology, 65(3), 586-596. Doi:10.1037/0022-3514.65.3.586

Sage, N. A., \& Kindermann, T. A. (1999). Peer networks, behavior contingencies, and children's engagement in the classroom. Merrill-Palmer Quarterly, 45(1), 143171.

Salmivalli, C. (2010). Bullying and the peer group: A review. Aggression And Violent Behavior, 15(2), 112-120. doi:10.1016/j.avb.2009.08.007 
Smith, D. S., \& Juvonen, J. (2017). Do I fit in? Ramifications of low gender typicality in early adolescence. Journal of Adolescence. doi:10.1016/j.adolescence.2017.07.014. Advance online publication.

Stoddart, T., \& Turiel, E. (1985). Children's concepts of cross-gender activities. Child Development, 56(5), 1241-1252. doi:10.2307/1130239

Swain, S. D., Weathers, D., \& Niedrich, R. W. (2008). Assessing three sources of misresponse to reversed Likert items. Journal Of Marketing Research, 45(1), 116131. doi:10.1509/jmkr.45.1.116

Toomey, R. B., Ryan, C., Diaz, R. M., Card, N. A., \& Russell, S. T. (2013). Gendernonconforming lesbian, gay, bisexual, and transgender youth: School victimization and young adult psychosocial adjustment. Psychology of Seuxal Orientation and Gender Diversity, 1(S), 71-80. doi:10.1037/2329-0382.1.S.71

Webb, H. J., \& Zimmer-Gembeck, M. J. (2014). The role of friends and peers in adolescent body dissatisfaction: A review and critique of 15 years of research. Journal Of Research On Adolescence, 24(4), 564-590. doi:10.1111/jora.12084

Weijters, B., Baumgartner, H., \& Schillewaert, N. (2013). Reversed item bias: An integrative model. Psychological Methods, 18(3), 320-334. doi:10.1037/a0032121

Wessler, S. L., \& De Andrade, L. L. (2006). Slurs, stereotypes, and student interventions: Examining the dynamics, impact, and prevention of harassment in middle and high school. Journal of Social Issues, 62(3), 511-532. doi:10.1111/j.15404560.2006.00471.x

Yunger, J. L., Carver, P. R., \& Perry, D. G. (2004). Does gender identity influence 
children's psychological well-being?. Developmental Psychology, 40(4), 572-582. doi:10.1037/0012-1649.40.4.572

Zosuls, K. M., Andrews, N. Z., Martin, C. L., England, D. E., \& Field, R. D. (2016). Developmental changes in the link between gender typicality and peer victimization and exclusion. Sex Roles, 75(5-6), 243-256. doi:10.1007/s11199016-0608-z 
Michelle Jennine Tam

\section{EDUCATION}

B.A. in Psychology

\section{HONORS AND FELLOWSHIPS}

Royster Special Distinction Award, University of Kentucky $(\$ 15,000)$

Psychology Fellowship, University of Kentucky $(\$ 40,300)$

James Miller Award

Patterson Scholarship, University of Kentucky $(\$ 145,000)$

National Merit Scholarship, National Merit Scholarship Corporation $(\$ 2,500)$

Georgia Scholar, Georgia Department of Education

\section{PROFESSIONAL PUBLICATIONS}

Brown, C.S., Tam, M.J., \& Aboud, F.E. (2018). Ethnic prejudice in young children in Indonesia: Intervention attempts using multicultural friendship stories. International Journal of Early Childhood, 50(1), 67-84. doi.org/10.1007/s13158-018-0214-z.

Brown, C.S., \& Tam, M.J. (in press). Parenting girls and boys. In M.H. Bornstein (Ed.), Handbook of parenting (3rd ed.). New York, NY: Routledge. 